\title{
J(৫)
}

Received: 06.06.2020

Accepted: 08.06.2020

Published: 14.06 .2020

\section{RENTZSCH, J. \& H. YILDIZ. The Uybat Inscriptions: a Group of Old Turkic Runic Texts from the Yenisei Area, De Gruy- ter, Berlin/Boston, 2020, 146 pp. ISBN: 978-3-11-067448-4}

\author{
Erdem UçAR \\ Friedrich-Schiller-Universität Jena (Jena/Germany) \\ E-mail: erdem.ucar@uni-jena.de
}

Bugün Tuva ve Hakasya cumhuriyetleri sınırları içerisinde (Sibirya bölgesinde) yer alan Türk Runik harfli yazıtlar XVII. yüzyılın sonlarından itibaren bilinmektedir. Bu yazıtların Yenisey yazıtları adıla daha geniş çevrede tanınıp üzerinde araştırmalar yapılmaya başlanması XIX. yüzyılda mümkün olmuştur. Kağanlık yazıtlarından daha önce bulunup incelenmeye başlansa da Yenisey yazıtlarının araştırılması Kağanlık yazıtları kadar çok olamamıştır. Bunun nedeni muhtemelen yazıtların hiçbirinde tarih olmaması ve içerikleri bakımından Kağanlık yazıtlarına nazaran daha sivil karakterde olması gösterilebilir.

Elimizdeki çalışma, sayısı iki yüzü aşan Yenisey yazıtları envanterinden Uybat adıyla bilinen sekiz yazıt (VASILYEV'in numaralandırmasıyla E 30, E 31, E 32, E 33, E 34, E 98, E 83 ve E 132) üzerine yeni bir neşirdir. Yazıtlardan bazılarının ilk 


\section{$J(\Theta)$}

nâşiri olan RADLOFF, bulunma yeri Uybat nehri olduğu için onlara bu adı koymuştur. Uybat VIII'de (E 132) taşın üzerinde herhangi bir metin yoktur, ama yazarlar yine de neşirlerine yazıtı dâhil etmiştir.

I. Introduction bölümünde (s. 1-8), sekiz taşın bulunma yeri ve neşir tarihi hakkında kısaca bilgi verilerek yazıtlar tanıtılmıştır. Yazıtların tarihlendirilmesiyle ilgili olarak, daha önceki araştırmacıların VII. yüzyılın ikinci yarısından başlayıp X. yüzyıla kadar varan çeşitli tarihler önerdiği söylenmiştir. Kitapta, sekiz yazıt üzerindeki 36 satırlık veya $743 \sim 745$ oyukluk (harflik) metnin yeni bir neşrinin gerçekleştirildiğinden bahsedilmiştir. Yazarlar, sekiz yazıtta toplam 40 tane farklı glyph (= oyuk) veya işaret olduğunu düşünmektedir.

Eserde kullanılan, glyph (oyuk) teriminin biraz riskli olduğunu söylemeliyim. Mesela, yazarların <š> ve <ŝs olarak gösterdiği iki harf aynı ünsüzü göstermektedir, yani yazıda ayırıcı bir vasfa sahip değildir. Bu nedenle bunların iki farklı glyph olduğunu söylemek pek kolay değildir. Aynı şekilde, $<\mathrm{n}>$ ve $<\dot{\mathrm{n}}>$ işaretleri de müstakil bir glyph değil, aynı işaretin bir varyantı gibidir. Bunların ayrı bir glyph olarak değerlendirilmesi ne kadar doğrudur emin değilim.

Kitapta kullanılan harfçevrim ve yazıçevrim işaretleri için A. BERTA'nın Kağanlık yazıtları neşrinde kullandığı işaretler esas alınmış, ama doğal olarak bazı harfler için yenilerinin eklenmesi zorunlu olmuştur. Runik işaretlerin harfçevriminde ön damak ve arka damak karşıtlığına sahip ünsüzler için küçük ve büyük harf kullanma ilkesi benimsenmiştir. Bu uygulama oldukça pratiktir, ancak ben pratikliğin arttırılması ve okuyucunun faydası adına bu konuda küçük bir değişiklik yapılması gerektiğine inanıyorum. Eserde, /o/ ve /u/ karşıllı̆ındaki harf için büyük W, /ö/ ve /ü/ karşıllğındaki harf için de yine büyük Ẅ kullanılmıştır. Aynı şekilde ön damak /k/'si için küçük $\mathbf{k}$, ama arka damak /k/'si için büyük $\mathbf{K}$ kullanılmıştır. Büyük ve küçük harf kullanma yönteminde böyle bir tercih tutarlılığ sağlamak için zorunluktur. Ancak büyük W ve Ẅ yerine küçüklerini kullanmanın ve arka damak /k/'si için küçük q ve ön damak /k/'si için de küçük k harfi kullanmanın okuyucu açısından çok daha fazla yararlı olacağı aşikârdır.

Giriş bölümünün ardından her biri ayrı bir bölümde ele alınarak sekiz yazıtın neşri yapılmıştır: Uybat I (s. 9-21), Uybat II (s. 22-30), Uybat III (s. 31-69), Uybat 


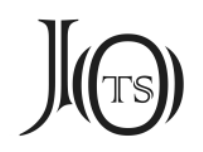

IV (s. 70-75), Uybat V (s. 76-80), Uybat VI (s. 81-93), Uybat VII (s. 94-96) ve Uybat VIII (s. 97).

Neşirde, her yazıt ayrıntılı olarak ele alınmıştır. Buna göre, ilk olarak yazıt hakkında bilgi verilip neşir tarihinden kısaca bahsedilmiş, ardından yazıtta kullanılan glyph'ler listelenmiştir. Böylece hangi yazıtta hangi harf için özel bir işaret kullanıldığı görülebilmektedir. Neşirde, yazıttaki her satırın daha önceki neşirlerdeki harfçevriminin ve yazıçevriminin nasıl yapıldığı gösterilmiş ve farklılıklar açıklanmıştır. Bu anlamda neşirdeki paleografik incelemenin gayet başarılı olduğunu söyleyebilirim. Ancak eski neşirlerden Recebov-Memmedov 1993'ün çalışmada kullanılmadığı görülmektedir. Bu eserde Uybat yazıtları hakkında farklı okuma ve açıklama önerileri bulunmaktadır.

Yazarlar, her satırı bağımsız olarak incelerken daha önceki okuma önerilerini gösterdikten sonra kendi okuyuşlarını ve tercümelerini R-Y [Rentzsch-Yıldız] kısaltması kullanarak sunmuştur. Bununla beraber, satırlardaki sorunlu ibareler hakkında açıklamalar da yapılmıştır.

Yazıtların kopyasını veya harfçevrimini veren daha önceki çalışmalarda bazen her araştırmacı bir satırı tamamen farklı okuyup anlamlandırmıştır. Bunun nedeni yazıtlardaki oyukların yıpranmış olması ve farklı işaretlerin tanımlanmasındaki zorluktur. Bu nedenle, Yenisey yazıtları ile ilgili neşir işinin kolay olmadığını söylemeliyim. Kitapta, bu zorluğun bilincinde olunarak metne azamî dikkat gösterilmeye çalışılmıştır. Yazarlar, yazıtlardan bazılarının muhafaza edildiği Minusinsk müzesine gidip onların yeni bir kopyasını almamış, daha önceki kopyalardan yararlanarak yazıtları yorumlamayı tercih etmiştir.

Neşrin sunuluşunu daha iyi görebilmek adına neşirden örnek iki sayfanın resmini aşağıda paylaşmak istiyorum: 


\section{$J(\Theta)$}

(3) $\quad[\mathrm{FA}(1) ; \mathrm{R} 2(\mathrm{~F} 4+\mathrm{R} 1) ; \mathrm{M}(4+11) ; \mathrm{V}(\mathrm{IV}+\mathrm{XI}) ; \mathrm{K}(8) ; \mathrm{BZ}(1) ; \mathrm{AY}(4+11)]$

[FA] I[1 ${ }^{44} \mathrm{~m} \ldots$ gn:TWKz:r ... d ...:tz:g ... AW ... :TN:rg ... Rr ... p[n $]^{45}$

[R1] gnTWKz ... tzgI ... np: ... TN:rglg

[R2] \{(F4) gn:TWKn $\}$ (“R1”) ... tzgInp:TN:rglg ... $\}$

[0] $\quad\{($ F4) gn:TWKn $\}$ (“"R1”) ... TWKz ... tzgInp:TN:rglg ... $\}$

[M] $\quad\{(4)$...gn:TWKz $\}\{(11) \ldots$ TWKz:tzgInp:TN:rglg ... $\}$

[V] $\quad\left\{(\mathrm{IV}) \ldots\right.$ gn:TWKz $\left\{\right.$ (XI) TWKz ... tzgInp ${ }^{46}:$ TN:rglg $\}$

[K1] Ilm ... gn:TWKz:rg ... tzgn[dI]:TN:rg[TR] ...

[K2] Ilm ... gn:TWKz:rg ... tzgn[dI]:TN:rg[TR] ...

[BZ] ... gn:TWKz ... tzgn ... :TN:rg

[AY] $\{(4) \ldots$ gn:TWKz $\}\{(11) \ldots$ gn:TWKz ... tzgn ... :TN:rg $\}$

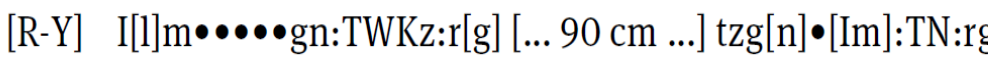

Uybat III/3. satırın harfçevrimi (s. 37)

(3)

[R2] <(F4) ... toquz > ("R1") täzginip atïn ärklig ...>

[O] $<$ (F4) ... gin toquz $><$ ("R1”) ... [toquz] ${ }^{92}$... täzginip atïn ärglig ...>

[M] <(4) ...gn toquz ><(11) ... [toquz] täzginip atïn äriglig>

[K1] ilim ... gn toquz ärig ... täzgindi tan (?) ärig tar ...

[K2] ilim ... gn toquz ärig ... täzgindi tan (?) ärig tar ...

[BZ] ... älim ... gn toquz ... tizgin ... atun ärig

[US] ilim ... kn toquz ärig ... täzgindi tan ärig tar ...

[AY] <(4) ... gn toquz><(11) [bä]gin toquz ... täzgin[tim] atïn ärig>

[R-Y] e[l]im<dä> ...gXn toquz är[ig] ... täzgi[n]<D $>$ [im] atïn ärig ...

\section{Uybat III/3. satırın yazıçevrimi (s. 57)}

Neşirdeki bazı okunuşlara ve yorumlamalara kısaca değinmem gerekiyor.

Uybat III/1. (s. 34, 53) ve 13. satırda (s. 48, 66) geçen YwqLDI imlâlı kelime CLAUSON'a dayanılarak yokal- olarak yorumlanmıştır (s. 55). Kelimenin imlâsı onun yokladı şeklinde okunmasına da uygundur. Fiil benzer imlâyla Oznaçennaya I (E 25) yazıtının 6. satırında (Aydın 2019: 97) geçmektedir. Yazarların tercih ettiği yokal-'ın fiil kökü *yoka- Eski Türkçede şimdiye değin tanıklanmamıştır. Üs- 


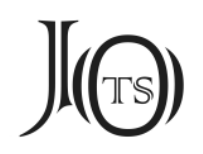

telik yokal- fiilinin Eski Türkçedeki en erken tanıkları (Clauson 1972: 902b) Kutadgu Bilig'in geç tarihli yazmalarında tespit edilmiştir. Bence Uybat/III'teki kelime yokla- 'yok olmak, kaybolmak' olmalıdır. Eski Türkçede Uygurcadan itibaren pek çok metinde yokla- fiiline rastlanmaktadır. ERDAL, 'yükselmek' ve 'yok olmak' anlamında iki farklı yokla- olduğunu düşünse de (1991: 452-453), aslında iki fiil de bence aynı olmalıdır.

Uybat III/7. satırda geçen uruyusı hakkındaki açılamada (s. 61), uruøu için KoRMişin gibi 'sancaktar' anlamında karar kılınmıştır. Eski Türkçede uruyu'nun 'bayrak' anlamını sadece Orta Türkçe dönemindeki çift dilli kaynaklardan öğrenebiliyoruz (Clauson 1972: 236a-b). Türkçe, eğer erken dönemde Moğolcaya kelimeyi ödünç verdiyse, kelimenin 'sancak, bayrak' anlamını tekrar değerlendirmek faydalı olabilir. Nitekim GABAIN kitabında kelimeyi sadece 'alp' anlamında göstermiştir (1950: 347b). ERDAL'in kelimeye verdiği 'general' anlamı kabul edilebilir gözüküyor, ama onun ornu okuma önerisi (1991: 79-80) şüphelidir, zira kelimenin ur- fiili ile ilişkisi oldukça açıktır. Üstelik Eski Uygurcada uruyut'un ikinci hecedeki yuvarlak ünlüsünün yazıldığı tanıklar bulunmaktadır. Bu durum kelimenin okunuşunun dahi yeniden değerlendirilmesi gerektiğini düşündürmektedir. Ayrıca yazıtta uruju'nun ınançu ile beraber kullanımına bakılırsa, uruju'nun 'alp' anlamında düşünülmesi daha muhtemel gözükmektedir.

Uybat III/15. satırda ẅ[gய̈]rp imlâsıyla geçen kelime için ö[gü]r(e)p okunuşu önerilmiş ve Eski Türkçede ögüre- (< ögür+e-) fiilinin ilk kez burada tanıklandığı iddia edilmiştir (s. 67). Kelimenin geçtiği yerdeki okunuş net değildir. Ayrıca, tarihî ve günümüz Türk dillerinde *ögüre- 'bir araya gelmek, toplanmak' diye bir fiil başka bir yerde görülmüyor. Bu nedenle böyle bir teklifin ilave delillere ihtiyacı olduğu açıtırı.

Uybat VI/6. satırda geçen BGw imlâsına sahip kelime bugu 'erkek geyik' olarak düşünülmüş (s. 87, 91) ve Drevnetyurkskiy Slovar'a dayanılarak bugu'nun ilk kez Oğuzname'de görüldüğü söylenmiş ve kelimenin ilk geçtiği yerin artık Uybat VI yazıtı kabul edilebileceği iddia edilmiştir (s. 93). Yazarların bahsettiği Oğuznâme'nin, daha doğru bir ifadeyle Pagan Oğuznamesi'nin dili Orta Türkçedir ve orada geçen bugu Moğolcadan alıntıdır (Danka 2019: 280). Bu nedenle, yazıttaki bugu için başka bir teklifin düşünülmesi gerekmektedir. 


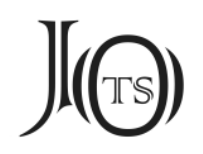

Uybat VII'de geçen çwy imlâsına sahip kelimenin Türk dillerindeki çoy 'büyük' ile ilgili olabileceği, ama bu kelimenin de en erken Dîvânu Lugâti't-Türk'te görüldüğü söylenmiş, belki de ilk geçtiği yerin Uybat VII yazıtı olabileceği ifade edilmiştir (s. 95-96). CLAUSON, Kaşgarî’nin çoy et 'kemiksiz et' olarak kaydettiği çoy'u Çince 重 zhong 'yoğun' kökenli olarak tahmin etmiştir (1972: 424b). CLAUsoN'un da belirttiği üzere bu sözcük Eski Türkçede tekörnek (hapax) özelliğindedir, bu nedenle kelimenin kökenine ve varlığına ihtiyatla yaklaşılmalıdır. Diğer

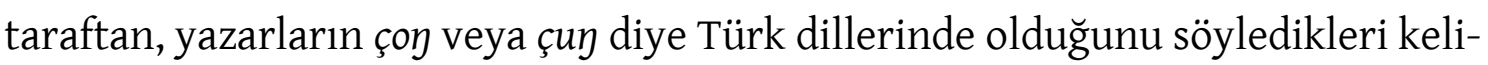
menin çōn şekli de vardır ve onun da Eski Türkçe yogun yogan'a dayandığı (Stachowski 1996: 219) tahmin edilmektedir. Bu nedenle yazıttaki çwy hakkında yorum yapmanın şimdilik zor olduğu söylenebilir.

Eserde, her yazıtın neşri ayrı bir bölüm halinde verildikten sonra, sekiz yazıtın kararlaştırılan harfçevrimi, yazıçevrimi ve İngilizce tercümesi toplu hâlde verilmiş (s. 98-106), bunun ardından sekiz yazıtın sözlüğü (s. 107-114) ve ekler dizini (s. 115-117) sunulmuştur. Son kısımda, eserin kaynakçası (s. 118-120) ile yazıtların resimleri (s. 121-146) bulunmaktadır.

Sekiz farklı yazıttaki 36 satırlık metninin başarılı bir paleografik incelemesini sunan eserin ileride yapılacak çalışmalara sağlam bir zemin oluşturduğu rahatlıkla söylenebilir. Yazarları kutlarken, diğer Yenisey yazıtlarının neşirlerini de merakla beklediğimi ifade etmek isterim.

\section{Kaynakça}

AYDIN, E. (2019). Sibirya’da Türk İzleri Yenisey Yazttları, İstanbul: Kronik Kitap.

Clauson, Sir G. (1972). An Etymological Dictionary of Pre-Thirteenth Century Turkish, Oxford: Oxford University Press.

DANKA, B. (2019). The Pagan Oyuz-nāmä: a Philological and Linguistic Analysis, Wiesbaden: Harrassowitz Verlag.

ERDAL, M. (1991). Old Turkic Word Formation, a Functional Approach to the Lexicon I-II, Wiesbaden: Harrassowitz Verlag. 


\section{J(৫)}

GaBAIN, A. von (1950). Alttürkische Grammatik mit Bibliographie, Lesestücken und Wörterverzeichnis auch neutürkisch, 2. verbesserte Auflage, Leipzig: Harrassowitz Verlag.

RecEbov, E. \& Y. Memmedov (1993). Orhon-Yenisey Abideleri, Bakı: Yazıçı.

StachowsKi, M. (1996). "Einige chakassische Etymologien", Ural-Altaische Jahrbücher, Neue Folge, 14: 218-230. 